$$
\begin{array}{ll}
\text { Volume } & : 05 \\
\text { Nomor } & : 03 \\
\text { Bulan } & : \text { September } \\
\text { Tahun } & : 2019 \\
\text { http } & : / / \text { ejurnal.pps.ung.ac.id/index.php/AKSARA/index }
\end{array}
$$

\title{
SEGMENTASI PASAR DI HOTEL GRAND Q GORONTALO
}

\author{
Asminar Mokodongan \\ Dosen Universitas Negeri Gorontalo \\ asminarmokodongan@gmail.com
}

Received: 02 Juni 2019; Revised: 19 Juli 2019; Accepted: 25 Agustus 2019

\begin{abstract}
ABSTRAK
Penelitian ini ditujukan untuk memperoleh gambaran tentang segmentasi pasar pada Hotel Grand $Q$ Gorontalo. Penelitian ini menggunakan pendekatan deskriptif kualitatif dengan jenis penelitian survei. Teknik pengumpulan data menggunakan observasi, angket dan studi dokumentasi, dengan sasaran segmentasi geografis, demografis, dan psikografis. Mencermati hasil penelitian tentang segmentasi pasar pada Hotel Grand $Q$ Gorontalo ini dengan karakteristik pengunjung hotel sebagaimana digambarkan di atas, maka dapat disimpulkan bahwa wisatawan yang memilih untuk menginap di Hotel Grand $Q$ Gorontalo mayoritas merupakan pebisnis dengan fluktuasi jumlah pengunjung yang tergantung pada intensitas event penting yang diselenggarakan di Provinsi Gorontalo. Oleh karena itu disarankan sebaiknya Hotel Grand Q Gorontalo senantiasa melakukan analisis pasar secara efektif sehingga dapat menentukan strategi segmentasi pasar yang tepat, serta melakukan inovasi yang diarahkan pada peningkatan kualitas pengelolaan dan pelayanan.
\end{abstract}

Kata kunci: Segmentasi Pasar, Hotel Grand $Q$ Gorontalo

\section{PENDAHULUAN}

Hotel adalah bidang yang menawarkan jasa pelayanan seperti pelayanan terhadap penyediaan makanan dan minuman, akomodasi, transportasi dan masih banyak lagi yang fasilitas disediakan oleh suatu hotel untuk mendapatkan kepuasan pelanggan. Hotel merupakan sebuah industri yang menawarkan sejuta keramahtamahan di dalamnya. Di Indonesia industri perhotelan juga sudah cukup maju. Beberapa perusahaan hotel besar Indonesia yang telah melebarkan sayap ke taraf International sama halnya dengan perusahaan Hotel yang telah mendunia yang sedang memperbanyak cabang di Indonesia, tidak sedikit hotel yang didirikan dipenjuru Indonesia salah satunya di Provinsi Gorontalo.

Di Gorontalo sendiri saat ini perkembangan industri perhotelannya sangat pesat, dan juga cukup menyerap tenaga kerja. Di Gorontalo ada beberapa hotel besar yang cukup terkenal di masyarakat luas contohnya Grand Q Hotel, Maqna Hotel, Amaris Hotel, dan Damhil Training Center. Setiap hotel memiliki tujuan yang sama yaitu mendapatkan keuntungan dan pendapatan yang lebih untuk kemajuan hotel, dengan memberikan jasa pelayanan sebaik mungkin, sama halnya yang dilakukan oleh salah satu hotel di Gorontalo yakni Grand $Q$ Hotel.

Hotel Grand $Q$ yang merupakan hotel berbintang pertama di Gorontalo ini adalah hotel yang cukup terkenal dan memiliki banyak peminat dari masyarakat lokal maupun domestik. Dalam sejarahnya Grand $Q$ Hotelyang dulunya bernama Quality Hotel Gorontalo, dibangun pada tahun 2002 s/d 2005 dan diresmikan oleh Gubernur Gorontalo Ir,H. Fadel Muhamad, pada tanggal 20 mei 2005 dan ditetapkan sebagai tanggal lahirnya Quality Hotel Gorontalo. Kemudian pada tahun 2007 Quality harus mengganti nama hotel, seiring berjalannya waktu akhirya, tepat pada tanggal 01 januari 2014, pukul 00:00 Quality Hotel resmi berganti nama dan logo mejadi Grand $Q$ hotel yang diresmikan oleh bapak H.Wiranto beserta Ibu $\mathrm{Hj}$. Rugaiyah W Usman. Saat Ini Grand $Q$ merupakan hotel berbintang tiga yang berada di 


$\begin{array}{ll}\text { Volume } & : 05 \\ \text { Nomor } & : 03 \\ \text { Bulan } & : \text { September } \\ \text { Tahun } & : 2019 \\ \text { http } & : / / \text { ejurnal.pps.ung.ac.id/index.php/AKSARA/index }\end{array}$

Provinsi Gorontalo, Grand $Q$ merupakan Bisnis Hotel ini adalah Hotel yang juga banyak melakukan promosi untuk menarik minat pelanggan, untuk memasarkan produk yang disediakan oleh Hotel, Grand $Q$ telah melakukan promosi melalui berbagai media seperti media cetak yaitu, berkerja sama dengan pihak Gorontalo Post dan Radar Gorontalo, adapun media cetak lainnya seperti penyebaran Brosur pada setiap orang atau instansi tertentu, penepatan spanduk pada titik-titik tertentu yakni di Jl. Agus Salim, Jl. Jend, Sudirman, Bandara Djalaludin Gorontalo, Jl. Pangeran Hidayat, Limboto, perbatasan bone bolango dan beberapa titik lainnya di Gorontalo. Selain itu, Grand $Q$ juga memiliki media Online yang dapat diakses untuk melakukan pemesanan. Grand $Q$ juga telah melebarkan sayap ke luar daerah, seperti Manado dan Jakarta.

Dalam proses pemasaran ada beberapa hal dasar yang perlu diperhatikan, yakni kebutuhaan (needs), Keinginan (Wants), dan permintaan yang bervariasi dari konsumen.

Istijanto (2007:xiii) mengemukakan bahwa pemasaran adalah dunia yang menyentuh kita semua baik kita sebagai marketer yang memasarkan produk maupun sebagai konsumen yang mengkonsumsinya. Kalau kita cermati definisi pemasaran yang dibuat oleh American Marketing Association (AMA), maka kita dapati makna pemasaran. Disebutkan bahwa, "Marketing is an organizational function and a set of a proceses for creating, comunicating, and delivering value to customers and for managing customers relationship in ways that benefit the organition and its stakeholders." (www.marketing.com). Kalau diterjemahkan dalam Bahasa Indonesia, pemasaran diartikan sebagai suatu fungsi perusahaan dan serangkaian proses untuk menciptakan, mengomunikasikan, dan memberikan nilai ke pelanggan serta mengelola hubungan pelanggan yang memberikan manfaat bagi perusahaan dan pihak-pihak yang berkepentingan.

Menurut Budi (2003:81), suatu perusahaan tidak dapat terhubung dengan semua pelanggannya di pasar yang luas dan beragam. Pasar dapat dibagi atau disegmentasi dengan kebutuhan dan keinginan yang berbeda. Industri Hotel merupakan industri yang sangat kompetitif. Tidak mungkin untuk mengoperasikan sebuah hotel yang ditujukan untuk memuaskan keinginan semua pelanggan.

Maka dari itu segmentasi pasar bagi suatu hotel adalah orang perorangan dan organisasi yang membutuhkan produk mereka serta mempunyai kemampuan untuk membelinya. Segmen pasar terdiri dari pembeli potensial tertentu yang memenuhi kriteria yang sama. Kriteria berupa demografis (tujuan kunjungan, tingkat hunian, umur, pendapatan, dan gender) serta faktorfaktor situasi khusus. Suatu hotel pasti memiliki rencana untuk mensegmentasikan atau membagi keinginan dan kebutuhan oleh konsumen yang bervariasi.

Menurut Budi (2003:81) salah satu kunci kesuksesan sales and marketing hotel perusahaan terletak pada proses segmentasi, yang merupakan akar dari pernyataan di atas. Keberhasilan perusahaan tentu saja sangat bergantung pada pelanggannya, mulai dari siapa pelanggannya, bagaimana karakteristik pelanggan yang akan mempengaruhi proses pembelian, sampai bagaimana daya pelanggan semuanya ditentukan oleh segmentasi pasar jasa.

Di Grand $Q$ hotel memiliki tingkat hunian tersendiri, sebagian besar datang dari Group bertujuan untuk melakukan bisnis. Namun, tidak banyak tamu individual yang datang di Hotel Grand Q, promosi dilakukan berupa menawarkan fasilitas rekreasi seperti maeleo Restourant, the lounge and bar, Q-Corn Pub, Inbox Karoke, Internet Direct Conection, fasilitas rekreasi ini hanya $25 \%$ dari sebagian tamu yang menginap menggunakannya.

\section{Tabel 1.1}

Dasar segmentasi pasar pada Hotel Grand $Q$ Gorontalo 


$$
\begin{array}{ll}
\text { Volume } & : 05 \\
\text { Nomor } & : 03 \\
\text { Bulan } & : \text { September } \\
\text { Tahun } & : 2019 \\
\text { http } & : \text { //ejurnal.pps.ung.ac.id/index.php/AKSARA/index }
\end{array}
$$

\begin{tabular}{|c|c|c|}
\hline $\mathrm{NO}$ & SEGMENTASI VARIABEL & KETERANGAN \\
\hline 1. & $\begin{array}{l}\text { Geografis } \\
\text { - Wilayah } \\
\text { - Area Pasar } \\
\text { - Ukuran Kota }\end{array}$ & $\begin{array}{l}\text { Jl. Nani Wartabone, Kota Selatan, } \\
\text { Kota Gorontalo } \\
\text { Gorontalo, Manado, dan Jakarta } \\
\text { KM atau Sekitar 0:53 64.79 \% dari } \\
\text { area Provinsi Gorontalo. Secara } \\
\text { Geografi ,Kota Gorontalo terletak } \\
\text { antara 000 } 28 \text { ' } 17 \text { " - } 00035 \text { ' } 56 \text { " } \\
\text { bujur utara ( BU ) dan } 122059 \text { ' } 44 \\
\text { "-1230 05'59 " Bujur Timur (BT) }\end{array}$ \\
\hline 2 & $\begin{array}{ll}\text { Demografis } \\
\text { - } & \text { Umur } \\
\text { - } & \text { Pendidikan } \\
\text { - } & \text { Jenis Kelamin } \\
& \\
\text { - } & \text { Pendapatan } \\
\text { - } & \text { Ukuran Keluarga } \\
\text { - } & \text { Siklus ukuran keluarga } \\
\text { - } & \text { Tingkat hunian } \\
& \\
\text { - } & \text { Agama }\end{array}$ & $\begin{array}{l}30^{\text {th }}-50^{\text {th }} \\
\text { Universitas, Pekerja } \\
\text { Pria } 75 \% \\
\text { Wanita } 25 \% \\
\text { Rp.50.000.000/hari } \\
\text { Rp.1.200.000.000/Bulan } \\
1 \text { and } 2 \text { Members Max } \\
\text { Menikah, tanpa anak, anak muda } \\
1350 \text { kamar/bulan } \\
\text { Group : } 70 \% \\
\text { Individual : } 25 \% \\
\text { Muslim : } 85 \% \\
\text { Dll : } 15 \%\end{array}$ \\
\hline 3 & $\begin{array}{cc}\text { Psikografis } \\
- & \text { Kelas Sosial } \\
- & \text { Gaya Hidup }\end{array}$ & $\begin{array}{l}\text { Pemerintah, pekerja } \\
\text { Konservatif. Liberal }\end{array}$ \\
\hline
\end{tabular}

Sumber: Grand Q Hotel 2016

\section{METODE PENELITIAN}

Penelitian ini menggunakan pendekatan deskriptif kualitatif dengan jenis penelitian survei. Pendekatan dan jenis penelitian ini memungkinkan peneliti untuk dapat mendeskripsikan temuan-temuan penelitian sehingga dapat menyajikan data akurat terutama yang berkaitan dengan segmentasi pasar pada hotel Grand $Q$ Gorontalo.

Menurut Wardiyanta (2010:5) penelitian deskriptif (descriptif research) adalah penelitian yang bertujuan membuat deskriptif atas suatu fenomena sosial/alam secara sistematis, faktual, dan akurat. Di samping itu, penelitian ini juga sering digunakan untuk menguji suatu hipotesis atau untuk menjawab pertanyaan mengenai berbagai peristiwa yang sedang terjadi di masyarakat.

HASIL PENELITIAN DAN PEMBAHASAN

Hasil dan Pembahasan Segmentasi Pasar di Hotel Grand $Q$ Gorontalo 


$\begin{array}{ll}\text { Volume } & : 05 \\ \text { Nomor } & : 03 \\ \text { Bulan } & : \text { September } \\ \text { Tahun } & : 2019 \\ \text { http } & : \text { /lejurnal.pps.ung.ac.id/index.php/AKSARA/index }\end{array}$

\section{Segmentasi Pasar Berdasarkan Geografi}

Segmentasi pasar geografi di bagi menurut tempat dan wilayah asal. Segmentasi geografi sangat berguna dalam dunia pemasaran untuk menemukan keinginanan kebutuhan dari konsumen yang bervariasi bahkan yang sama berdasarkan daerah asal konsumen. Berikut ini adalah tabel yang menunjukan segmentasi pasar asal wisatawan berdasarkan geografi di hotel Grand $Q$ Gorontalo. Berikut ini adalah tabel tingkat kunjungan wisatawan berdasarkan segmentasi geografi.

Tabe 14.1 Tingkat Kunjungan Berdasarkan Segmen Pasar Berbasis Geografi

\begin{tabular}{|c|c|c|c|c|c|}
\hline \multirow{2}{*}{$\begin{array}{l}\text { Segmen pasar } \\
\text { Berbasis } \\
\text { Geografi }\end{array}$} & \multicolumn{5}{|c|}{ Jumlah Wisatawan } \\
\hline & 2011 & 2012 & 2013 & 2014 & 2015 \\
\hline Lokal & 5500 & 6000 & 7000 & 6.500 & 8000 \\
\hline \begin{tabular}{cl}
\multicolumn{2}{l}{ Domestic } \\
- Jakarta \\
- Bandung \\
- Surabaya \\
- Makasar \\
- Manado
\end{tabular} & $\begin{array}{l}1000 \\
500 \\
800 \\
1500 \\
2500\end{array}$ & $\begin{array}{l}1500 \\
500 \\
700 \\
2000 \\
3000\end{array}$ & $\begin{array}{l}2000 \\
1000 \\
700 \\
2000 \\
1500\end{array}$ & $\begin{array}{l}1000 \\
800 \\
600 \\
2000 \\
1000\end{array}$ & $\begin{array}{l}1500 \\
700 \\
500 \\
1500 \\
2500\end{array}$ \\
\hline $\begin{array}{cl}\text { Luar negeri } \\
\text { - } & \text { Malaysia } \\
\text { - } & \text { Singapore } \\
\text { - } & \text { Belanda } \\
\text { - Perancis } \\
\text { - German } \\
\text { - } \text { China }\end{array}$ & $\begin{array}{l}200 \\
150 \\
250 \\
200 \\
50 \\
200\end{array}$ & $\begin{array}{l}100 \\
50 \\
150 \\
70 \\
50 \\
20\end{array}$ & $\begin{array}{l}300 \\
200 \\
100 \\
100 \\
150 \\
50\end{array}$ & $\begin{array}{l}400 \\
500 \\
300 \\
600 \\
200 \\
70\end{array}$ & $\begin{array}{l}90 \\
80 \\
100 \\
100 \\
200 \\
100\end{array}$ \\
\hline
\end{tabular}

Sumber: data primer 2016 Hotel Grand Q

Berdasarkan tabel 4.1 diatas dapat dilihat bahwa pengunjung/tamu hotel Grand Q tidak saja berasal dari wilayah sendiri (lokal), akan tetapi juga berasal dari wilayah lain di luar provinsi Gorontalo maupun dari manca negara. Pengunjung hotel dari wilayah lokal mendominasi jumlah pengunjung domestik dan luar negeri. Selama rentang tahun 2011 sampai dengan 2015 jumlah kunjungan ke hotel ini rata-rat mengalami peningkatan signifikan terutama pengunjung lokal. Dari wilayah domestik kunjungan didominasi oleh pengunjung yang berasal dari daerah Manado, diikuti oleh Makasar dan Jakarta, Bandung dan Surabaya. Pengunjung hotel yang berasal dari luar negeri meliputi mereka yang berasal dari Malaysia, Singapura, Perancis, Belanda, Jerman, dan Cina. Pengunjung yang berasal dari mancanegara ini mengalami fluktuasi. Pada tahun 2011 sampai dengan 2014 tingkat kunjungan mengalami peningkatan dalam jumlah, akan tetapi pada tahun 2015 mengalami penurunan, kecuali Jerman tetap stabil dan Cina mengalami sedikit peningkatan.

\section{Segmentasi Pasar Berdasarkan Demografi.}




$$
\begin{array}{ll}
\text { Volume } & : 05 \\
\text { Nomor } & : 03 \\
\text { Bulan } & : \text { September } \\
\text { Tahun } & : 2019 \\
\text { http } & : \text { //ejurnal.pps.ung.ac.id/index.php/AKSARA/index }
\end{array}
$$

Segmentasi demografi merupakan segmentasi yang berfungsi untuk membedakan wisatawan lebih efisien berdasarkan umur, jenis kelamin, agama, pendapatan, pendidikan, status perkawinan, penghasilan, dan sebagainya. Segmentasi demografi merupakan cara yang paling efektif dan paling mudah untuk mengenali wisatawan. Berikut ini beberapa tabel yang menujukan segmentasi pasar berbasis demografi.

Tabel 4.2 Segmentasi Pasar Demografi Berbasis Umur Wisatawan.

\begin{tabular}{|l|l|l|}
\hline $\begin{array}{l}\text { Segmentasi Wisatawan } \\
\text { Berdasarkan Umur }\end{array}$ & Jumlah & Persentase \\
\hline$\leq 18$ & 2 & $6,6 \%$ \\
$18^{-} 35$ & 5 & $16,7 \%$ \\
$35-60$ & 20 & $66,7 \%$ \\
$\geq 60$ & 3 & $10 \%$ \\
& & \\
\hline TOTAL & 30 & $100 \%$ \\
\hline
\end{tabular}

Sumber: data primer 2016 Hotel Grand Q

Tabel 4.2 diatas menggambarkan bahwa dari pengunjung setiap hari yang diperkirakan berjumlah 30 orang, terdapat $66,7 \%$ merupakan pengunjung yang berusia 35-60 tahun, diikuti oleh persentasi mereka yang berusia 18-35 tahun (16,7\%), 10\% di atas 60 tahun dan 6,6\% yang berusia di bawah 18 tahun. Melihat persentase pengunjung berdasarkan usia ini, dapat dimaklumi jika pengunjung yang berusia 35-60 tahun merupakan jumlah yang paling besar mengingat pengunjung hotel ini lebih banyak didominasi pengunjung yang memiliki urusan bisnis.

Tabel 4.3 Tabel Segmentasi Demografi Berbasis Agama.

\begin{tabular}{|l|l|l|}
\hline $\begin{array}{l}\text { Segmentasi } \\
\text { WisatawanBerdasarkan } \\
\text { Agama }\end{array}$ & Jumlah wisatawan & Persentase \\
\hline Islam & 25 & $83,3 \%$ \\
\hline Kristen & 2 & $6,7 \%$ \\
\hline Katolik & 1 & $3,3 \%$ \\
\hline Protestan & 1 & $3,3 \%$ \\
\hline Hindu & 1 & $3,3 \%$ \\
\hline Budha & - & - \\
\hline TOTAL & $\mathbf{3 0}$ & $\mathbf{1 0 0 \%}$ \\
\hline
\end{tabular}

Sumber: data primer 2016 Hotel Grand $Q$

Tabel 4.3 di atas menggambarkan bahwa jumlah pengunjung hotel Grand Q mayoritas beragama Islam $(83,3 \%)$ diikuti oleh pengunjung beragama Kristen (6,7\%), Katolik, Protestan dan Hindu $(3,3 \%)$. Dengan demikian dapat di simpulkan bahwa bahwa wisatawan paling banyakadalah yang beragam Islam dan paling sedikit adalah Katolik, Protestan dan Hindu. Persentase pengunjung yang beragama Islam mendominasi jumlah pengunjung yang beragama lain karena dari segmentasi berbasis geografis pengunjung yang terbanyak adalah pengunjung 


$$
\begin{array}{ll}
\text { Volume } & : 05 \\
\text { Nomor } & : 03 \\
\text { Bulan } & : \text { September } \\
\text { Tahun } & : 2019 \\
\text { http } & : \text { //ejurnal.pps.ung.ac.id/index.php/AKSARA/index }
\end{array}
$$

lokal atau yang berasal dari wilayah provinsi Gorontalo sendiri. Hal ini dapat dimengerti karena sebagian besar penduduk Gorontalo, bahkan Indonesia, mayoritas beragama Islam.

Tabel 4.4 Segmentasi Demografi Berbasis Pendapatan

\begin{tabular}{|l|l|l|}
\hline $\begin{array}{l}\text { Segmentasi wisatawan } \\
\text { berdasarkan pendapatan }\end{array}$ & Jumlah & Persentase \\
\hline$\leq$ Rp. 1.850.000,- & 3 & $10 \%$ \\
\hline Rp. 1.850.000,- - Rp. 3.000.001- & 15 & $50 \%$ \\
\hline Rp. 3.000.000,- - Rp. 5.000.000,- & 10 & $33,3 \%$ \\
\hline$\geq$ Rp. 5.000.000,- & 2 & $6,7 \%$ \\
\hline TOTAL & $\mathbf{3 0}$ & $\mathbf{1 0 0 \%}$ \\
\hline
\end{tabular}

Sumber data primer Grand Q Hotel 2016

Tabel 4.4diatas menunjukan bahwa wisatawan yang berkunjung ke hotel Grand $Q$ memiliki pendapatan yang bervariasi. Dari jumlah pengunjung hotel Grand $Q$ dalam jumlah rata-rata 30 orang per hari, maka pendapatan tertinggi yakni dengan jumlah pendapatan Rp. 1.850.000,- Rp. 3.000.001-(50\%), diikuti oleh yang memiliki pendapatan Rp. 3.000.000,- Rp. 5.000.000,$(33,3 \%)$, pendapatan $\leq$ Rp. $1.850 .000,-(10 \%)$ dan yang memiliki pendapatan di atas 5.000 .000 ,- sebanyak 6,7\%. Jika dihubungkan dengan pengunjung hotel yang dominan berasal dari penduduk lokal, maka dapat dipahami bahwa pendapatan yang berkisar antara Rp. 1.850.000,- - Rp. 3.000.001- adalah mereka yang memiliki pekerjaan sebagai Pegawai Negeri Sipil maupun swasta yang jumlah pendapatan mereka kurang lebih sama dengan nilai pendapatan tersebut.

Tabel 4.5 Tingkat Segmentasi Demografi Berdasarkan Tabungan

\begin{tabular}{|l|l|l|}
\hline $\begin{array}{l}\text { Segmentasi wisatawan } \\
\text { berdasarkan tabungan }\end{array}$ & Jumlah & Persentase \\
\hline$\leq$ Rp. 950.00,- & 10 & $33,3 \%$ \\
\hline Rp. 950.001,- - Rp. 1.500.001- & 15 & $50 \%$ \\
\hline Rp. 1.500.000,- - Rp. 2.500.000,- & 3 & $10 \%$ \\
\hline ZRp. 2.500.000,- & 2 & $6,7 \%$ \\
\hline TOTAL & $\mathbf{3 0}$ & $\mathbf{1 0 0 \%}$ \\
\hline
\end{tabular}

Sumber data primer Grand Q 2016

Berdasarkan tabel 4.5 di atas, dapat dilihat bahwa kemampuan menabung para pengunjung dapat dilihat dengan jelas dari yang paling sedikit hingga yang paling banyak. Segmentasi berbasis tabungan ini didominasi oleh pengunjung dengan kemampuan menabung paling tinggi adalah sejumlah Rp. 950.001,- - Rp. 1.500.001- (50\%). Peringkat berikutnya adalah dengan kemampuan menabung di bawah Rp. 950.000,- $(33,3 \%)$, selanjutnya diikuti oleh kemampuan menabung sejumlah Rp. 1.500.000,- - Rp. 2.500.000,- (10\%) dan $\geq$ Rp. 2.500.000,- (6,7\%). Kemampuan menabung dalam jumlah di atas Rp. 2.500.000,- memiliki persentase yang paling kecil karena rata-rata pendapatan pengunjung dari segmentasi berbasis pendapatan rata-rata berkisar antara Rp. 1.850.000,- - Rp. 3.000.001,-. Hal ini juga berkaitan dengan segmentasi pengunjung berdasarkan geografis yang bekerja sebagai PNS dengan pendapatan yang relatif sama dengan jumlah yang ada di atas. 


$$
\begin{array}{ll}
\text { Volume } & : 05 \\
\text { Nomor } & : 03 \\
\text { Bulan } & : \text { September } \\
\text { Tahun } & : 2019 \\
\text { http } & : \text { //ejurnal.pps.ung.ac.id/index.php/AKSARA/index }
\end{array}
$$

Tabel 4.6 Tingkat Segmentasi Berdasarkan Dana Liburan

\begin{tabular}{|l|l|l|}
\hline $\begin{array}{l}\text { Segmentasi wisatawan berdasarkan } \\
\text { dana liburan }\end{array}$ & Jumlah & Persentase \\
\hline$\leq$ Rp. 1.000.000,- & 14 & $46,7 \%$ \\
\hline Rp. 1.000.000,- - Rp. 3.000.001,- & 10 & $33,3 \%$ \\
\hline Rp. 3.000.000,- - Rp. 5.000.000,- & 4 & $13,3 \%$ \\
\hline$\geq$ Rp. 5.000.000,- & 2 & 6,7 \\
\hline TOTAL & $\mathbf{3 0}$ & $\mathbf{1 0 0 \%}$ \\
\hline
\end{tabular}

Sumber data primer 2016 Hotel Grand Q

Tabel 4.6 diatas menunjukan bahwa pengunjung hotel berdasarkan segementasi demografi berbasis dana liburan, paling tinggi memiliki dana untuk liburan sebesar $\leq \mathrm{Rp}$. 1.000.000,- dan untuk jumlah dana yang paling rendah adalah $\geq \mathrm{Rp}$. 5.000.000,-. Jika dilihat dari jumlah kunjungan rata-rata 30 orang/hari maka dapat dirincikan bahwa dari jumlah ini terdapat 46,7\% pengunjung yang memiliki dana liburan $\leq \mathrm{Rp}$. 1.000.000,-. Peringkat berikut ditempati oleh yang memiliki dana liburan yang berkisar antara Rp. 1.000.000,- - Rp. 3.000.001,- (33,3\%), Rp. 3.000.000,- - Rp. 5.000.000,- $(13,3 \%)$ dan yang paling rendah adalah dana liburan $\geq$ Rp. $5.000 .000,-(6,7 \%)$.

Berdasarkan tabel ini dapat ditarik kesimpulan bahwa pengunjung hotel Grand Qhanya sedikit memiliki dana liburan. Ini dapat disebabkan oleh dekatnya lokasi hotel Grand Q sebagai tempat berlibur bagi keluarga sehingga dana liburan yang disiapkan juga lebih sedikit. Demikian pula jika dihubungkan dengan segementasi pengunjung berdasarkan geografis dan demografis (umur dan pendapatan), maka hal jumlah dana liburan ini sudah sesuai dengan rentang pendapatan yang sudah disebutkan di atas.

\section{Strategi Segmentasi Pasar Hotel Grand QGorontalo}

Strategi merupakan tindakanyang diarahkan pada upaya peningkatan dan dilakukan secara terus-menerus berdasarkan sudutpandang tentang apa yang diharapkan oleh para pelanggan di masa depan.Dengan demikian perencanaan strategi hampir selalu dimulai dari "apa yangakan terjadi", bukan dimulai dari "apa yang terjadi". Terjadinya kecepataninovasi pasar baru dan perubahan pada pola konsumen memerlukan kompetensiinti dalam bisnis yang dilakukan. Hotel, sebagaiman juga perusahaan bisnis lain perlu mencari kompetensi inti di dalam bisnis yang dilakukan. Strategi merupakan kekuatan yang mendorong motivasi bagi stakeholder (manajer, karyawan, konsumen,komunitas, pemerintah dan sebagainya) baik secara langsung maupun tidaklangsung yang menerima keuntungan atau biaya yang ditimbulkan oleh tindakan yangdilakukan oleh perusahaan, dalam hal ini hotel.

Berdasarkan penelitian yang telah dilakukan bahwa Grand $Q$ telah melakukan strategi segmentasi berupa pengelompokan konsumen untuk berbisnis. Seharusnya Grand $Q$ melakukan segmentasi pasar bedasarkan segmentasi Geografi, demograi dan psikografi, agar lebih teliti dalam membedakan keinginan dan kebutuhan konsumen, serta bisa mendatangkan lebih banyak lagi konsumen untuk berwisata ataupun hanya untuk bersenang-senang. Adapun strategi yang telah dilakukan yaitu dengan melakukan promosi, penempatan spanduk, penyebaran spanduk, iklan radio maupun iklan surat kabar. Namun belum juga mendatangkan lebih banyak lagi kosumen untuk berwisata. Walaupun, hotel ini menamakan dirinya hotel 


$\begin{array}{ll}\text { Volume } & : 05 \\ \text { Nomor } & : 03 \\ \text { Bulan } & : \text { September } \\ \text { Tahun } & : 2019 \\ \text { http } & : \text { //ejurnal.pps.ung.ac.id/index.php/AKSARA/index }\end{array}$

bisnis namun perlu ada konsumen yang seimbang karena secara geografi, hotel ini terletak dipusat kota yang memiliki kawasan strategi untuk berwisata serta fasilitas yang tersedia.

Melihat segementasi pasar yang ada di Hotel Grand $Q$, maka faktor lain yang juga sangat mendukung adalah adanya komunikasi yang baik dan efisien. Strategi dalam menciptakan dan menjaga komunikasi dapat menjamin keberlangsungan proses pengelolaan hotel yang baik yang pada akhirnya dapat turut meningkakan kualitas layanan hotel secara keseluruhan. Promosi adalah suatu bentuk komunikasi pasar, yakni suatu aktivitas pemasaran untuk menyebarkan informasi, mempengaruhi, mengingatkan pasar sasaran atas perusahaan dan produk hotel sehingga bersedia menggunakan produk atau fasilitas yang ditawarkan oleh pihak hotel. Dari berbagai semgmen pengunjung hotel baik berdasarkan geografis, demografis dan psikografis, maka hal yang paling penting dilakukan sebagai strategi segmentasi pasar Hotel Grand Q adalah dengan meningkatkan kualitas yang konsisten baik dari segi pengelolaan dan kemudahan pelayanan hotel, dan meyakinkannya kepada konsumen melalui berbagai strategi komunikasi yang efektif.

\section{PENUTUP}

Berdasarkan hasil penelitian yang telah dipaparkan pada bab sebelumnya, maka dapat dikemukakan kesimpulan bahwa Segmentasi pasar pada Hotel Grand $Q$ mencakup segmentasi pasar berdasarkan geografi, demografi dan psikografi. Dari segmen pasar dari segi geografi, pengguna layanan hotel Grand $Q$ lebih didominasi oleh penduduk domestik/lokal. Dari segi demografi, pengguna hotel mayoritas berusia antara 35 s.d 60 tahun. Segmentasi pasar sangat penting dilakukan di hotel Grand $Q$ agar hotel Grand $Q$ dapat diversifikasi layanan untuk memenuhi keinginan dan kebutuhan konsumen yang berbeda-beda. Segmentasi pasar dalam rangka memenuhi kebutuhan konsumen atau pelanggan hotel dilakukan dengan cara promosi dengan menggunakan fasilitas spanduk, iklan radio maupun iklan surat kabar.

\section{DAFTAR PUSTAKA}

Assauri, Sofjan. 2007. Manajemen Pemasaran. Jakarta: Rajawali Press.

Baygono., dan Sambodo, Agus. 2006. Dasar-dasar Kantor Depan Hotel. Bandung: Alfabeta. Baygono. 2012. Teori dan Praktik Hotel front Office. Bandung: Alfabeta.

Bojanic, David C, \& Shea, Linda J. 1997. Segmentation for a multiunit Restaurant Operation. Cornel Hotel \& RestaurantAdministration Quarterly, pg. 56-61.

Budi, Agung Permana, 2013. Manajemen Marketing Perhotelan. Yogyakarta: CV Andi Offset.

Ghert, kenneth C., \& Shim, Soyean. 2013. Sitiuational Segmentation in the International Marketplace: The Japanese Snack Market. International Marketing Review, p. 180-194. Istijanto, 2007. 63 Kasus Pemasaran Terkini Indonesia Membedah Strategi dan Taktik Pemasaran Baru. Jakarta:PT Elexmedia komputindo.

Kasali, Rhenald. 1998. Membidik Pasar Indonesia Segmentasi, Targeting, Positioning. Jakarta, PT Gramedia Pustaka Utama.

Kasali, Rheinald. 2000. Manajemen Public Relation. Jakarta: PT Temprint.

Kasali, Rheinald. 2008. Manajement Public Relation. Konsep dan Aplikasinya di Indonesia. Jakarta: Pustaka Utama Grafiti. 